\title{
Investigation of a Smoke Toxicity Fire Model for Use on Wood
}

\author{
MARCELO M. HIRSCHLER and GREGORY F. SMITH \\ B. F. Goodrich \\ Technical Center, Avon Lake, Ohio 44012, USA
}

\section{ABSTRACT}

Experiments were carried out to investigate the effect of burning conditions on combustion of Douglas fir wood in a proposed smoke toxicity test: a plastic $200 \mathrm{~L}$ exposure chamber with a radiant furnace. Research included effects of: incident heat flux, sample surface, initial oxygen level and endpoint criteria.

Wood board sample mass can vary broadly even at equal surface and thickness, suggesting that surface may not be an ideal surrogate for amount of material. The effect of carbon black on ignitability is erratic. Ignitability of blackened wood samples is higher than that of unblackened samples only if both are identical. Irreproducibility increases at low incident fluxes.

Tests carried out with the IT50 concept are hazardous to the operator (oxygen addition can cause explosions) and lead to high irreproducibility (sixfold variations of co doses in identical tests).

Yields of co depend on exposure protocol and on sample size. At high initial oxygen levels, however, C0/C02 ratios are very low, unless big samples are burnt to completion. This leads to excessive smoke for toxicity purposes. The $\mathrm{C0}$ yields and $\mathrm{C} 0 / \mathrm{CO} 2$ ratios are adequate when using very low oxygen levels $(0-5 \%)$ and high heat fluxes, conditions which simulate those in ventilation controlled fully developed fires.

\section{INTRODUCTION}

In the 1970's and early 1980's test methods were developed to measure smoke toxic potency. The ones most widely used are in refs. 1-4. These tests differ in several respects but they have served to show that the toxic potency of smoke from most materials is very similar [5-8]. In fact, the range of toxic potency for almost all combustible materials is less than an order of magnitude. These small differences were the cause for the different rankings in a study of toxic potencies of 14 materials by two methods [9]: the material ranked most toxic by one protocol was ranked least toxic by the other one! Neither of these protocols is in use now, but the work illustrates problems of such toxic potency tests. Smoke is not a uniform material: its composition depends on generation conditions. The same material can thus give smoke of very different composition and toxicity, depending on combustion conditions. 
The NFPA Quarterly discussed in 1933 [10] that the main direct cause of death in fires has always been combustion product toxicity. Smoke has two main types of toxicants: asphyxiants and irritants. The individual toxicant associated with the largest fire hazard is carbon monoxide (CO).

Co, a combustion product of any organic material, appears in all fires. When present in blood, it forms carboxyhemoglobin (COHb). While the exact lethal COHb level depends on individual characteristics, values $>20 \%$ can lead to death [11]. At least $60 \%$ of fire deaths have $50 \%$ $\mathrm{COHb}$, while > $>91 \%$ of fire victims have levels $>20 \% \mathrm{COHb}$ [12]. Recent statistical analyses of large data bases involving carbon monoxide from fire and non-fire sources have shown that, once the controlling factors of age, disease and blood alcohol level have been accounted for, the $\mathrm{COHb}$ distribution from fire and non-fire fatalities are very similar [13]. Although many other gases are contained in smoke, two studies where fire fighters visited actual buildings on fire, equipped with gas monitors $[14,15]$ concluded that the main hazardous toxicant in fire is co.

In the United States, most fire fatalities (specially if they are overcome by smoke inhalation) are remote from the fire origin room and follow a fire that has left its original room [7], suggesting that the fire may have reached "flashover". For such fires, specially if they are controlled by ventilation, smoke toxicity is dominated by co levels. In such fires too, full scale co levels are determined mainly by oxygen availability, which is, in turn, affected by variables such as geometry, ventilation, configuration, turbulence and mixing, and only somewhat influenced by chemical properties of the products being burnt [16]. Thus, co levels in such fires are critical for toxic hazard [17].

As a first approximation fires can be subdivided in three types [18]:

(1) Non flaming/smouldering fires

(2) Early or small flaming fires

(3) Fully developed large scale (post flashover) fires.

Smouldering fires occur with low heat inputs $\left(20 \mathrm{~kW} / \mathrm{m}^{\wedge} 2\right)$ and high oxygen levels. They generally give high carbon monoxide/carbon dioxide $(\mathrm{CO} / \mathrm{CO2})$ ratios, but within low yields of smoke altogether, and rarely affect people other than those intimate with ignition (typically seated in the upholstered furniture or bedding item first ignited). Small flaming fires occur with higher heat inputs $\left(20-35 \mathrm{~kW} / \mathrm{m}^{\wedge} 2\right)$ and fairly high oxygen levels. The yields of smoke are much higher than in smouldering fires but not yet high enough to affect people far from the fire, i.e. only in the room of fire origin. Fully developed fires generally involve very high heat inputs $\left(35 \mathrm{~kW} / \mathrm{m}^{\wedge} 2\right)$ and very low oxygen levels (close to zero). The results are extremely high smoke yields and $\mathrm{CO} / \mathrm{CO} 2$ ratios. These fires are overwhelmingly responsible for the fire fatalities found away from the source of the fire. In these cases, most products are virtually pyrolysed and $\mathrm{CO}$ is the dominant toxic factor.

This study looks at several issues associated with using a radiant apparatus with a protocol suggested for smoke toxicity. The fuel used in the investigation was Douglas fir, mainly because wood combustion has been studied very widely and is well understood. In view of the crucial importance of co levels in wood smoke toxicity, the emphasis of the research was placed on carbon oxide yields, under various conditions. 


\section{EXPERIMENTAL}

\section{Materials}

The fuel used for these experiments was Douglas fir wood, $19 \mathrm{~mm}$ (0.75") thick. All the wood used had a single source, so that its water content and density were fairly uniform. The wood was kept at ca. room temperature and $50 \%$ relative humidity until use.. The carbon black used to blacken the surface was Raven 410 (Columbian Chemicals).

\section{Apparatus and Procedure}

The apparatus used has a plastic exposure chamber, (Volume ca. 200 L), identical to that used in the NBS cup furnace toxic potency test [2] and a quartz combustion chamber. The heat source are 4 infrared lamps, set out symmetricaliy on two sides of the sample; the incident energy can be varied by changing incident flux or irradiation time (IT). The sample dimensions can vary, up to a maximum of $76 \times 127 \mathrm{~mm}$ ( 3 " $\times 5^{\prime \prime}$ ), with a maximum thickness of $51 \mathrm{~mm}\left(2^{\prime \prime}\right)$. The igniter is a sparker, placed $25 \mathrm{~mm}$ above the centre of the sample. Gases were analysed by pumping smoke through standard analysers (non dispersive infrared for $\mathrm{CO}$ and $\mathrm{CO} 2$ and paramagnetic for oxygen) and recirculating the smoke. Mass loss was measured with a load cell. A carbon black layer was added with a brush, in some experiments, in order to get a homogeneous black surface.

Tests I.I and II.I both invoived normal air and samples were burnt for a long time (until burning virtually ceased). Tests I.2 and II.2 differed from I.I and II.I only in that the starting atmosphere had $18 \%$ oxygen; in 1.3 and II.3 starting atmospheres had just enough oxygen to cause flaming ignition (12-14\%). In tests I.4 and II.4, burning started in air, but nitrogen was added rapidiy, to ramp the oxidant concentration to $4 \%$ oxygen in a few minutes; in I.5 and II.5, oxygen was added, to ensure oxygen concentrations $16 \%$. In tests labelled III, the initial sample surface was $9677 \mathrm{~mm}^{\wedge} 2$ (15 $\left.\mathrm{in}^{\wedge} 2\right)$, and the end point was a smoke concentration sufficient to cause a lethal $\mathrm{CO}$ atmosphere (IT50 mode). Tests labelled IV were carried out to investigate the effect of very low oxygen levels $(0,5,10 \%)$, at a fixed surface area simulating pyrolys is in vitiated atmospheres (high intensity ventilation-controlled fires). The V-VII series of tests had carbon black on the sample surface, while the VIII series were tests similar to I.1 or II.1, but with pairs of samples specially selected from the same Douglas fir wood board, to investigate ignition time, in the absence and presence of carbon black.

\section{RESULTS}

The procedures followed were designed towards investigating different different ways in which the apparatus could be used as a smoke toxicity test. In particular, two protocols have been proposed for use with this apparatus. The Smoke Toxicity Working Group at NIBS (National Institute of Building Sciences) [19] suggested the use of an IT50 concept (time of irradiation required to create a lethal atmosphere killing half $(50 \%)$ the exposed animals). More recently, NIST (National Institute of Standards and Technology) suggested a novel way of measuring smoke toxicity with the hardware, based on corrected LC50 values [20]. Table 2 contains some basic results of the present study and will be discussed in detail. 
Type Flux Init. Oxygen Oxygen Addition $\mathrm{kW} / \mathrm{m}^{\wedge} 2 \quad \%$

\begin{tabular}{|c|c|c|c|c|c|c|}
\hline I. 1 & 50 & 21 & No & Consumption & No & $11-24$ \\
\hline 1.2 & 50 & 18 & No & Fixed time & No & 20 \\
\hline 1.3 & 50 & 13 & No & Fixed time & No & 20 \\
\hline 1.4 & 50 & 21 & Add nitrogen & Fixed time & No & 20 \\
\hline 1.5 & 50 & 21 & Yes: to $16 \%$ & Fixed time & No & 20 \\
\hline II. 1 & 30 & 21 & No & Fixed time & No & 20 \\
\hline II . 2 & 30 & 18 & No & Fixed time & No & 20 \\
\hline II. 3 & 30 & 13 & No & Fixed time & No & 20 \\
\hline 11.4 & 30 & 21 & Add nitrogen & Fixed time & No & 20 \\
\hline 11.5 & 30 & 21 & Yes: to $16 \%$ & Fixed time & No & 20 \\
\hline III.I & 50 & 21 & Yes & Predicted $\mathrm{CO}$ & No & IT50 \\
\hline III.2 & 30 & 21 & Yes & Predicted CO & No & IT50 \\
\hline III .3 & 50 & 18 & No & Predicted CO & No & IT50 \\
\hline III. 4 & 50 & 13 & No & Predicted CO & No & IT50 \\
\hline III. 5 & 50 & 21 & Add nitrogen & Predicted $\mathrm{CO}$ & No & IT50 \\
\hline III. 6 & 30 & 18 & No & Predicted Co & No & IT50 \\
\hline III. 7 & 30 & 13 & No & Predicted $\mathrm{CO}$ & No & IT50 \\
\hline III. 8 & 30 & 21 & Add nitrogen & Predicted $\mathrm{CO}$ & No & IT50 \\
\hline IV. 1 & 50 & 0 & No & Fixed time & No & 20 \\
\hline IV. 2 & 50 & 5 & No & Fixed time & No & 20 \\
\hline IV. 3 & 50 & 10 & No & Fixed time & No & 20 \\
\hline V.1 & 50 & 21 & No & Ignition & Yes & Ignition \\
\hline V. 3 & 50 & 14 & No & Ignition & Yes & Ignition \\
\hline V. 5 & 50 & 21 & Yes: to $16 \%$ & Consumption & Yes & Ignition \\
\hline VI.I & 30 & 21 & No & Fixed time & No & 20 \\
\hline VII.I & 50 & 21 & Yes & Predicted co & No & IT50 \\
\hline VIII.I & 50 & 21 & No & Ignition & Yes & Ignition \\
\hline VIII. & 50 & 21 & No & Ignition & No & Ignition \\
\hline VIII .3 & 30 & 21 & No & Ignition & Yes & Ignition \\
\hline VIII & 30 & 21 & No & Ignition & No & Ignition \\
\hline
\end{tabular}

The first interesting result in this study was variability of mass for a specified surface area and thickness (Figure 1). In fact, the mass range for the $5800 \mathrm{~mm}^{\wedge} 2$ samples is $>30 \mathrm{~g}$ (while the average mass is only 50-60 g). This has already been found before in other wood burning studies, but it indicates an inherent irreproducibility inevitable when using surface area for wood toxicity results rather than sample mass.

The effect of carbon black on ignitability yielded curious results. In series VIII, sets of identical samples were cut from a single wood board; half of them were tested covered with a carbon black layer and the other half uncovered. The blackened samples ignited more readily than the unblackened ones, but with poor reproducibility. Samples, at random (series V-VII), were also tested covered with carbon black, and compared with samples run under apparently identical conditions, but not designed specifically for direct comparison. The results showed no clear trends. It appears that the relative locations of sample and igniter al though fixed in the apparatus are critical and thus smoke can pass close to the sparker without becoming ignited. This is especially noticeable at the lower incident flux, and is exacerbated by the use of carbon black. 
The most important issue investigated was the yield of carbon oxides: $\mathrm{CO}$ and carbon dioxide (CO2). Peak concentrations of $\mathrm{CO}$ or $\mathrm{CO} 2$ both increase roughly proportionately to the initial sample surface, to the mass charged, and even to mass lost. However, this finding in itself is of little real interest, since it simply indicates that more carbon oxides are generated when more smoke is produced, without an indication of whether the quality (or toxicity) of the smoke changes. Of much more interest is the effect of mass lost (or mass charged) on carbon oxide yields, and their ratios, in different experiments.

The yield of a combustion product is the mass of product generated per mass of sample burnt $(\mathrm{g} / \mathrm{g})$. For species that do not decay, yields can probably be calculated equally well from peak concentrations or from integrating the concentration-time curve over a fixed time period (which for all these experiments was set at $30 \mathrm{~min}$ ). In fact, the two values turned out to be quite different, with the value calculated from peak concentrations invariably higher than that calculated from integrated amounts. Interestingly, differences between results were not the same for both carbon oxides: in almost all cases the ratio of carbon monoxide to carbon dioxide calculated from peak values appeared higher than that calculated from integrated amounts of carbon oxides. Results discussed in this paper refer to yields from integrated values. Carbon balances were not made, since no soot or unburnt hydrocarbons were measured.

Results of Individual series

Tests of type 1.1 were carried out with small sample surfaces ( 3870 $\mathrm{mm}^{\wedge} 2,6 \mathrm{in}^{\wedge} 2$ ); CO yields (from integrated $\mathrm{CO}$ values) ranged between 0.006 and 0.056 , with a weak positive dependence on mass loss (almost within experimental noise). Carbon dioxide yields ranged from 0.26 to 0.75 , with a strong negative dependence on mass loss. The ratio of carbon oxides $(\mathrm{CO} / \mathrm{CO} 2)$ was low, but ranged from 0.025 to 0.165 , with an accelerating positive dependence on mass loss. This refers to successive experiments, indicating that yields of both carbon oxides are affected by sample mass charged and time of exposure. Time to ignition ranged from 0.55 to $1.75 \mathrm{~min}$; the differences, however, seem unrelated to mass loss or sample surface, so that time to ignition is $1.02 \pm 0.27 \mathrm{~min}$.

Tests of type 11.1 (with incident flux level of $30 \mathrm{~kW} / \mathrm{m}^{\wedge} 2$ ) had higher Co yields than the corresponding type I.l tests. There did not appear to be a dependence on sample mass loss. The CO2 yields were lower than those for type 1.1 tests, but had a very similar negative dependence on mass loss. The ratio of carbon oxides appeared to be slightly higher than for Type 1.1, with a similar type of dependence. Time to ignition was much higher than for Type I.1 tests, which is very logical because less energy is applied. It ranged from 2.4 to $4.95 \mathrm{~min}$, and appeared to increase with sample surface.

Tests of Type 1.2 gave higher co yields and lower CO2 yields than Type I.1 tests. They resembled Type II.l tests in their carbon oxide yields. They resembled the Type I.1 tests, however, in terms of their time to ignition, although the time to ignition appeared to be slightly higher than for Type I.1 tests. If the same type of test was carried out at a lower incident flux (Type II.2) this did not seem to make much difference to carbon oxide yields, but it raised the time to ignition, which, again, seemed to increase with sample surface. 
Table a Sunuary of the Results of the Douglas pir byperimats in the Radiant Lptaratus

Init, Init. Ign. Hass peak peak kin. Peak Integ, Integ, Integ. peak peak carbon

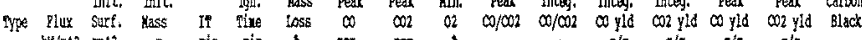

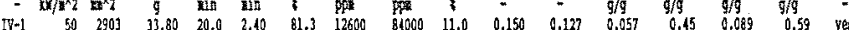

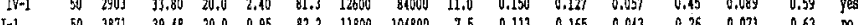

I-1 $\quad 50 \begin{array}{lllllllllllllll}5871 & 39.48 & 20.0 & 0.95 & 82.2 & 11800 & 104800 & 7.5 & 0.113 & 0.165 & 0.043 & 0.26 & 0.071 & 0.63 & \text { Do }\end{array}$

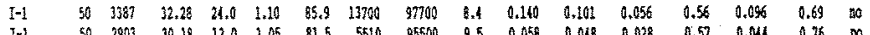

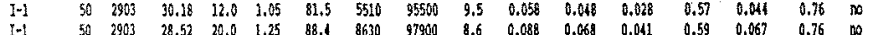

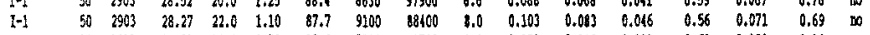

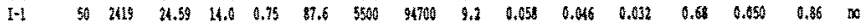

$\begin{array}{llllllllllllllllll}1-1 & 50 & 2419 & 24.15 & 20.0 & 0.90 & 86.5 & 6110 & 86800 & 10.4 & 0.070 & 0.051 & 0.032 & 0.54 & 0.056 & 0.80 & 0\end{array}$



$\begin{array}{lllllllllllllllll}1-1 & 50 & 1915 & 19.69 & 11.6 & 0.55 & 94.9 & 940 & 22500 & 18.4 & 0.042 & 0.035 & 0.006 & 0.17 & 0.010 & 0.24 & 10\end{array}$

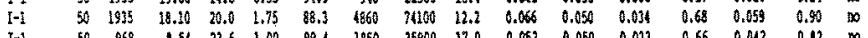

$\begin{array}{lllllllllllllllll}1-1 & 50 & 968 & 1.56 & 23.6 & 1.00 & 99.4 & 1850 & 35500 & 17.0 & 0.052 & 0.050 & 0.019 & 0.66 & 0.018 & 0.02 & 00\end{array}$

$\begin{array}{llllllllllllllll}50 & 968 & 8.50 & 20.0 & 0.95 & 103.2 & 1200 & 40200 & 16.5 & 0.030 & 0.025 & 0.019 & 0.75 & 0.027 & 0.89 & \text { In }\end{array}$

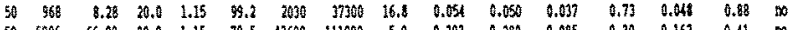

$\begin{array}{llllllllllllllll}50 & 5806 & 66.03 & 20.0 & 1.15 & 79.5 & 19600 & 111000 & 5.0 & 0.393 & 0.280 & 0.085 & 0.30 & 0.163 & 0.41 & 100\end{array}$

$\begin{array}{llllllllllllllll}50 & 2903 & 32.60 & 20.0 & 1.25 & \$ 1.3 & 11600 & 78400 & 9.0 & 0.146 & 0.130 & 0.060 & 0.16 & 0.086 & 0.58 & \text { no }\end{array}$

$59 \begin{array}{lllllllllllllll}5935 & 22.61 & 20.0 & 1.55 & 36.4 & 5920 & 70600 & 10.7 & 0.076 & 0.071 & 0.039 & 0.55 & 0.051 & 0.70 & 00\end{array}$

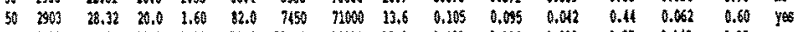

$\begin{array}{llllllllllllllll}50 & 5806 & 64.58 & 20.0 & 1.30 & 79.6 & 39900 & 92100 & 12.4 & 0.123 & 0.326 & 0.080 & 0.25 & 0.148 & 0.35 & 00\end{array}$

$\begin{array}{llllllllllllllll}50 & 3071 & 15.33 & 20.0 & 1.50 & 80.8 & 11400 & 31000 & 12.5 & 0.255 & 0.206 & 0.072 & 0.35 & 0.114 & 0.65 & \text { D }\end{array}$

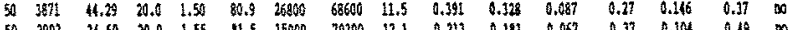

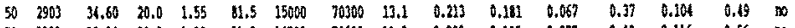

$\begin{array}{llllllllllllllll}50 & 2903 & 30.01 & 30.0 & 1.20 & 81.8 & 14700 & 70603 & 11.3 & 0.208 & 0.185 & 0.077 & 0.42 & 0.116 & 0.56 & \text { mo }\end{array}$

$\begin{array}{llllllllllllllll}50 & 1935 & 23.21 & 20.0 & 1.15 & 14.2 & 8700 & \$ 2500 & 13.3 & 0.205 & 0.130 & 0.0607 & 0.35 & 0.091 & 0.44 & 10\end{array}$

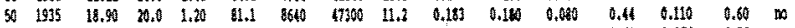

$\begin{array}{llllllllllllllll}50 & 968 & 10.00 & x 0.0 & 1.25 & 89.8 & 2600 & 34530 & 11.5 & 0.075 & 0.069 & 0.042 & 0.60 & 0.056 & 0.75 & 10\end{array}$

$\begin{array}{llllllllllllllll}50 & 968 & 9.69 & 20.0 & 2.00 & 92.5 & 1910 & 12300 & 13.4 & 0.060 & 0.056 & 0.032 & 0.57 & 0.062 & 0.70 & \text { in }\end{array}$

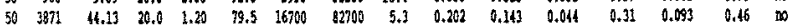

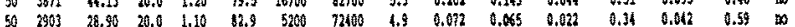

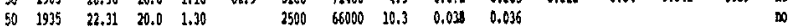

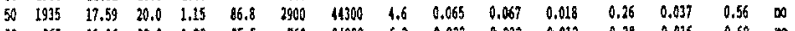

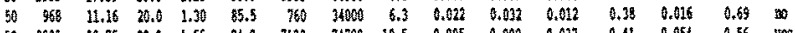

59 $\begin{array}{lllllllllllllll}2503 & 30.75 & 20.0 & 1.55 & 81.8 & 7130 & 74700 & 18.5 & 0.055 & 0.050 & 0.037 & 0.41 & 0.055 & 0.56 & \text { yes }\end{array}$

$\begin{array}{llllllllllllllll}50 & 5806 & 68.36 & 15.9 & 1.25 & 92.6 & 19600 & 120000 & 18.2 & 0.163 & 0.115 & 0.032 & 0.28 & 0.050 & 0.37 & \text { to }\end{array}$

$\begin{array}{lllllllllllllll}50 & 5806 & 67.48 & 15.0 & 1.10 & 80.0 & 22300 & 12680 & 0.177 & 0.134 & 0.048 & 0.36 & 0.080 & 0.45 & \text { no }\end{array}$

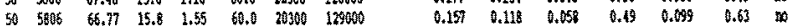

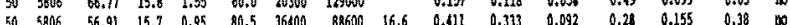

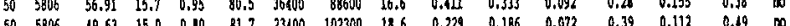

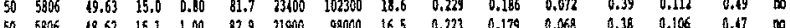

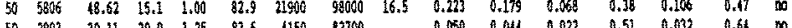

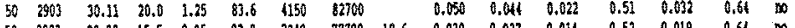

$\begin{array}{llllllllllllllll}50 & 2903 & 28.32 & 15.5 & 0.95 & 82.9 & 2340 & 77700 & 18.6 & 0.030 & 0.027 & 0.014 & 0.52 & 0.019 & 0.61 & \text { mo }\end{array}$

$\begin{array}{llllllllllllllll}50 & 2903 & 28.32 & 15.0 & 1.00 & 84.1 & 6910 & 70400 & 16.5 & 0.098 & 0.084 & 0.041 & 0.16 & 0.056 & 0.58 & 10\end{array}$

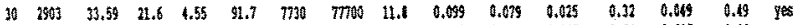

$\begin{array}{lllllllllllllll}30 & 5805 & 65.71 & 20.0 & 1.95 & 76.0 & 21700 & 96400 & 0.225 & 0.191 & 0.015 & 0.24 & 0.065 & 0.38 & \text { mo }\end{array}$

$\begin{array}{lllllllllllllll}30 & 3871 & 44.89 & 20.0 & 2.90 & 78.4 & 15200 & 86900 & 0.175 & 0.154 & 0.053 & 0.35 & 0.044 & 0.18 & 0.90\end{array}$

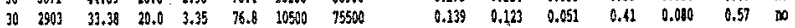

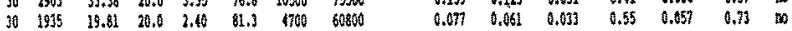

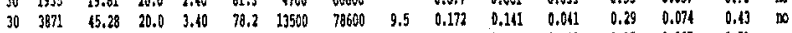

$\begin{array}{llllllllllllllll}30 & 2903 & 35.46 & 20.0 & 3.60 & 78.6 & 5560 & 79700 & 10.3 & 0.130 & 0.197 & 0.038 & 0.35 & 0.067 & 0.51 & 15\end{array}$

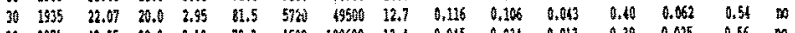

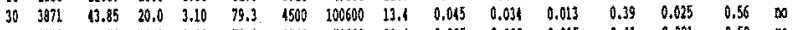

$\begin{array}{llllllllllllllll}30 & 2903 & 32.78 & 20.0 & 3.30 & 79.9 & 2760 & 79300 & 13.4 & 0.035 & 0.038 & 0.015 & 0.11 & 0.021 & 0.59 & 10\end{array}$

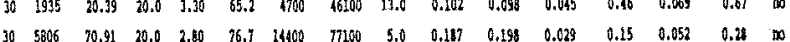

$\begin{array}{llllllllllllllll}30 & 3671 & 13.88 & 20.0 & 3.25 & 77.3 & 6310 & 31500 & 1.0 & 0.669 & 0.059 & 0.016 & 0.27 & 0.036 & 0.53 & 50\end{array}$

$\begin{array}{llllllllllllllll}30 & 2003 & 33.13 & 20.0 & 3.75 & 17.4 & 4.560 & 00700 & 5.3 & 0.057 & 0.057 & 0.017 & 0.29 & 0.035 & 0.61 & 30\end{array}$

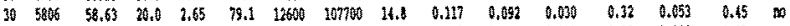

$\begin{array}{llllllllllllllll}30 & 3871 & 13.35 & 21.0 & 3.40 & 79.5 & 4200 & 83500 & 15.4 & 0.054 & 0.041 & 0.013 & 0.32 & 0.021 & 0.47 & 00\end{array}$

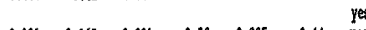

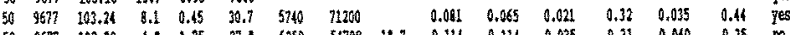

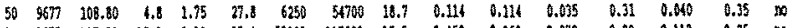

$\begin{array}{llllllllllllllll}50 & 9677 & 107.83 & 15.0 & 0.80 & 85.4 & 52900 & 117000 & 15.5 & 0.152 & 0.360 & 0.072 & 0.20 & 0.112 & 0.25 & 20\end{array}$

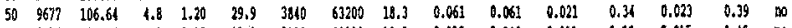

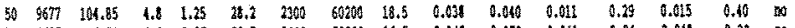

$\begin{array}{llllllllllllllll}50 & 9677 & 96.51 & 4.8 & 0.55 & 31.7 & 8009 & 53800 & 16.5 & 0.149 & 0.173 & 0.041 & 0.24 & 0.048 & 0.32 & \text { Do }\end{array}$

$\begin{array}{llllllllllllllll}50 & 9677 & 94.73 & 4.8 & 1.30 & 31.2 & 9530 & 51900 & 18.9 & 0.174 & 0.201 & 0.052 & 0.26 & 0.063 & 0.36 & 10\end{array}$

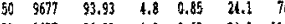

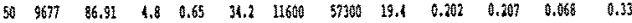

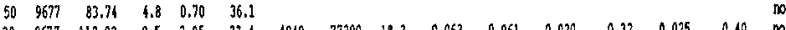

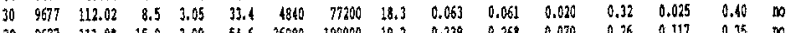

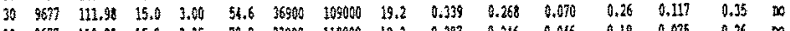

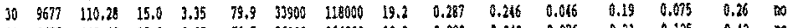

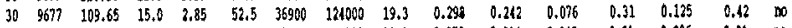

$\begin{array}{llllllllllllllll}30 & 9617 & 98.67 & 20.0 & 1.28 & 76.2 & 33260 & 119000 & 18.8 & 0.279 & 0.216 & 0.045 & 0.21 & 0.046 & 0.31 & \text { mo }\end{array}$

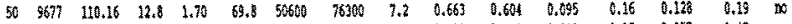

$\begin{array}{llllllllllllllll}50 & 9677 & 106.78 & 3.2 & 1.50 & 18.2 & 5830 & 17800 & 12.5 & 0.122 & 0.137 & 0.043 & 0.35 & 0.057 & 0.17 & 30\end{array}$

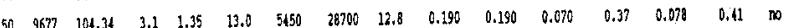

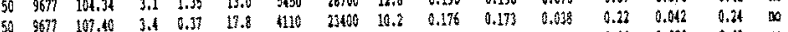

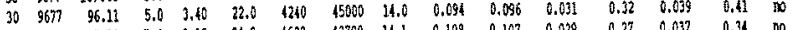

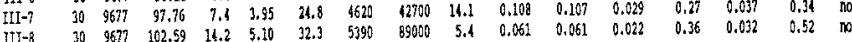


Tests of type I.3 again resulted in higher CO yields and lower $\mathrm{CO2}$ yields, but the $\mathrm{CO} / \mathrm{CO} 2$ ratios were higher than in type $\mathrm{I} .2$ tests. The times to ignition were somewhat higher than in earlier type I series, but did not seem to be greatly affected by sample surface area. If the same type of experiment was carried out at lower incident flux (II.3) the co yields decreased, the carbon dioxide yields increased and the $\mathrm{CO} / \mathrm{CO} 2$ ratios became very small. The times to ignition were similar to those of type II.2 samples, viz. > $3 \mathrm{~min}$.

A comparison of tests of type I.4 and I.3 shows substantial effects on the $\mathrm{CO}$ yields due to the change in conditions: they were much higher for I.3! However, the carbon dioxide yields were much less affected by the changes. The times to ignition were lower for I.4 than for I.3. Similar trends can be found on comparing II.3 and II.4.

Tests of Type $I .5$ and II.5 required severe precautions, because of the hazard involved in adding oxygen. In spite of this, an explosion occurred in one test. Such conditions pose serious risks to the test operator. These tests generated the highest $\mathrm{CO} 2$ yields of any test, as well as high $\mathrm{CO}$ yields and $\mathrm{CO} / \mathrm{CO} 2$ ratios. Times to ignition were low, averaging at $<1 \mathrm{~min}$, and appeared unaffected by surface sample area.

The NIBS protocol suggests that tests be stopped artificially at the time calculated to give an IT50, which, in the case of wood is determined exclusively from the Co concentration. For this work it was important to investigate the reproducibility of this. The tests carried out in the IT50 mode, i.e. done with the objective of determining the irradiation time needed to obtain a smoke concentration required to cause a lethal atmosphere to be created (Type III.1), gave low CO, high $\mathrm{CO} 2$ yields and very low times to ignition (<1 min). This was, at least partially, due to the oxygen addition. At the lower incident flux carbon oxide yields were similar, but times to ignition, naturally, increased considerably.

A series of experiments were made in which it was attempted to determine the reproducibility inherent in measuring an IT50. This was done through running an analytical pretest, by irradiating at $50 \mathrm{~kW} / \mathrm{m}^{\wedge} 2$, and maintaining oxygen concentrations at a level $16 \%$. The initial test run was used to measure the irradiation time required to obtain an integrated CO concentration time (CT) product of $100,000 \mathrm{ppm} \mathrm{min.}$

It was determined that, for a Douglas fir board $9677 \mathrm{~mm}^{\wedge} 2 \times 19 \mathrm{~mm}$, it took $290 \mathrm{~s}$ to obtain smoke containing a c0 dose of $100,000 \mathrm{ppm}$ min. Seven additional experiments were thus run, all of which were interrupted after an IT of $290 \mathrm{~s}$. The original sample masses were reasonably close, ranging from 86.9 to $108.8 \mathrm{~g}$, i.e. Well within the range indicated in Figure 1. The $30 \mathrm{~min}$ CO CT product was determined in all experiments and it ranged from a low of $52,000 \mathrm{ppm}$ min to a high of $311,800 \mathrm{ppm}$ min (average: $172,512 \mathrm{ppm} \min \pm 79,590 \mathrm{ppm} \min$ ): a sixfold variation!

In the experiments at very low initial oxygen levels the co yield was virtualiy unaffected by the initial oxygen concentration, but the $\mathrm{CO} 2$ yield showed two distinct areas: values of $0.05-0.1 \mathrm{~g} / \mathrm{g}$ at initial oxygen levels < $12 \%$ and values of 0.25 at initial oxygen levels > $12 \%$. Thus, the $\mathrm{CO} / \mathrm{CO} 2$ ratios also show the same dual trends: values of $0.9-1.4 \mathrm{~g} / \mathrm{g}$ at low oxygen levels and $<0.4 \mathrm{~g} / \mathrm{g}$ at high oxygen levels. None of the low oxygen experiments ( $10 \%$ ) caused ignition of the wood. 
An interesting overall observation is that if a similar sample mass was exposed to radiant heat, the $\mathrm{CO} / \mathrm{CO} 2$ ratio increased with IT. In fact, parallel straight lines could be drawn when increasing amounts of wood were exposed to irradiation times ranging from 11-12 min to $24 \mathrm{~min}$ (Figure 2). Both oxygen consumption rate and mass loss rate appeared to increase with the sample mass charged, although they did so at different rates: the mass loss rate increased faster than the oxygen consumption rate. The oxygen consumption rate can be equated to heat release rate, an indication of efficiency of combustion. Thus, the results mean that burning becomes less efficient as time goes on, as heat is released more slowly. On the other hand, oxygen consumption rate per unit area decreased as mass charged (or sample area exposed) increased (Figure 3 ).

\section{DISCUSSION}

The yields of carbon oxides (both $\mathrm{CO}$ and $\mathrm{C02}$ ) depend on several aspects, mainly the test conditions used and the sample mass burnt.

Perhaps the most important finding of this study is that the co yield is low for most experiments, ranging up to a value of ca. $0.16 \mathrm{~g} / \mathrm{g}$ mass lost. There is a very weak positive linear dependency of co yield on mass of sample burnt. The carbon dioxide yield, on the other hand, is much higher (ranging up to $>0.9 \mathrm{~g} / \mathrm{g}$ mass $10 \mathrm{st}$ ). Moreover it has a very strong negative linear dependency on sample mass lost. The combination of the two previous results means that the fitted ratio of $\mathrm{CO} / \mathrm{CO} 2$ ratio has a hyperbolic dependency on sample mass lost. In other words, this fitted ratio is very low at low sample mass lost values and increases until it reaches values of $>1$. However, by then over $90 \mathrm{~g}$ of sample have been burnt. Figure 4 shows the dependence of $C 0$ yield, CO2 yield, their fitted values and the fitted $\mathrm{CO} / \mathrm{CO} 2$ ratio on sample mass 10 st.

Innumerable smoke toxic potency tests have shown that typical toxic potencies are not too far away from values of $c a .30 \mathrm{mg} / \mathrm{L}$. Thus, in order to obtain a lethal atmosphere in the exposure chamber considered in this work (ca. $200 \mathrm{~L}$ ), smoke concentration above ca. $30 \mathrm{mg} / \mathrm{L}$, i.e. ca. 6 $\mathrm{g}$, would have no toxicological interest. At such levels of smoke, the $\mathrm{CO} / \mathrm{CO} 2$ ratio is only $\mathrm{Ca}$. < 0.1 for most experiments with high oxygen, i.e. very much lower than that for fires where there has been full room involvement. $0 n$ the other hand, the tests carried out under low oxygen conditions resulted in reasonably high $\mathrm{C} 0 / \mathrm{CO} 2$ ratios, probably quite representative of those found in fully developed fires. Thus, this chamber might be ideally suited for use to simulate fulity developed fires, if low initial oxygen levels are used. However, this would result in non flaming processes. If this is undesirable, it may be necessary to adjust the Co yields to obtain a value that fits the level found in fully developed full scale fires, e.g. as proposed by NIST [19].

\section{REFERENCES}

1. Levin, B.C., Fowe11, A.J., Birky, M.M., Paabo, M., Stolte A. and Malek, D., "Further Development of a Test Method for the Assessment of the Acute Inhalation Toxicity of Combustion Products", Nat. Bur. Stands, NBSIR 82-2532 (1982).

2. Alarie, Y. and Anderson, R.C. Tox. App1. Pharmacol. 11,341 (1979). 
3. Alexeeff, G.V. and Packham, S.C., J. Fire Sci. 2, 306 (1984).

4. Kimmerle, G., J. Combust. Toxicol. 1, 4 (1974).

5. Hirschler, M.M., J. Fire Sciences, $\frac{1}{5}, 289$ (1987).

6. Hirschler, M.M., in "Characterization and Toxicity of Smoke", (Ed. H.K. Hasegawa), ASTM STP 1082, Amer. Soc. Test. Mater., Philadelphia, PA, 1990 , p. 1 .

7. Levin, B.C. and Gann, R.G., in "Fire and Polymers", (Ed. G.L. Nelson), ACS Symp. Series 425, Amer. Chem. Soc., Washington, DC, 1990, p. 3.

8. Hirschler, M.M., in "Fire and Polymers", (Ed. G.L. Nelson), ACS Symp. Series 425, Amer. Chem. Soc., Washington, DC, 1990, p. 462.

9. Cornish, H.H., Hahn, K.J. and Barth, M.L., Env. H1th Perspect. 11, 191 (1975).

10. Ferguson, G.E., NFPA Quarter7y, 27(2), 110 (1933).

11. Nelson, G.L., Canfield, D.V. and Larsen, J.B., 11th. Int. Conf. Fire Safety (Ed. C. J. Hilado), p. 93, Prod. Safety, San Francisco, 1986.

12. Birky, M.M., Halpin, B.M., Caplan, Y.H., Fisher, R.S., McAllister, J.M. and Dixon, A.M., Fire Mats, 3, 211 (1979).

13. Debanne, S.M., Hirschler, M.M. and Nelson, G.L., in ASTM Symp. Fire Hazard and Fire Risk Assessment, December 5, 1990, San Antonio, TX.

14. Burgess, W.A., Treitman, R.D. and Gold, A., "Air Contaminants in Structural Firefighting", N.F.P.C.A. Project 7X008, Harvard School Public Health, 1979.

15. Grand, A.F., Kaplan, H.L. and Lee, G.H., "Investigation of Combustion Atmospheres in Real Fires", U.S.F.A. Project 80027, Southwest Research Institute, 1981.

16. Purser, D., in Int. Conf. on Fires in Buildings, (Ed. S.J. Grayson), 25-26 Sept. 1989, Toronto, Canada, Technomic, Lancaster, PA, p. 95.

17. Purser, D.A., in "Flame Retardants '90", British Plastics Federation, 17-18 January 1990, Elsevier, London, UK, 1990, p.206.

18. Roux, H.J., in Int. Conf. on Fires in Buildings, (Ed. S.J. Grayson), 25-26 Sept. 1989, Toronto, Canada, Technomic, Lancaster, PA, p. 115.

19. Babrauskas, V., 16th Int. Conf. Fire Safety, San Francisco, CA, 1991.

20. Babrauskas, V., Harris, R.H., Gann, R.G., Levin, B.C., Lee, B.T., Peacock, R.D., Paabo, M., Twilley, W., Yoklavich, M.F. and Clark, H.M., "Fire Hazard Comparison of Fire-Retarded and Non-Fire-Retarded Products," NBS Special Pub7. 749, July 1988, National Bureau of Standards, Gaithersburg, MD.

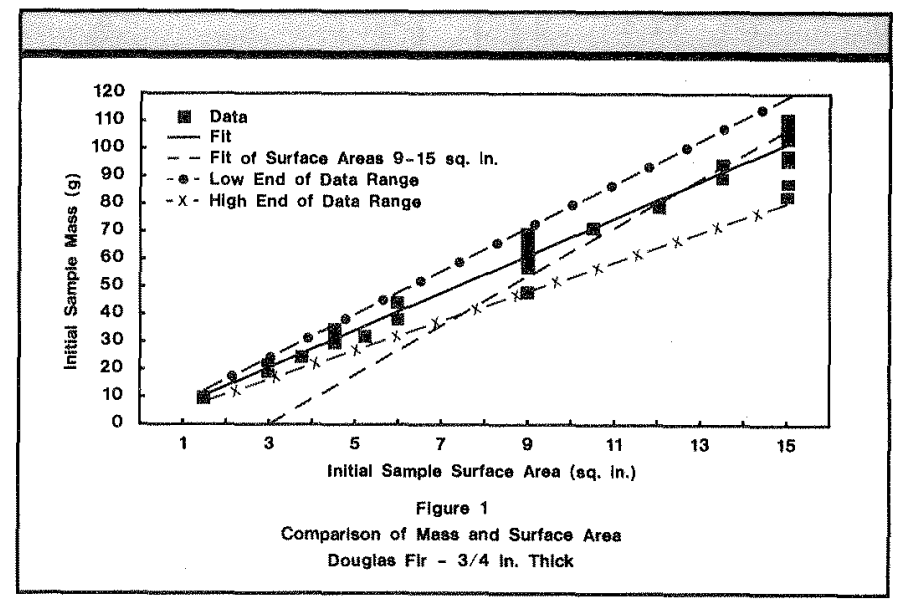



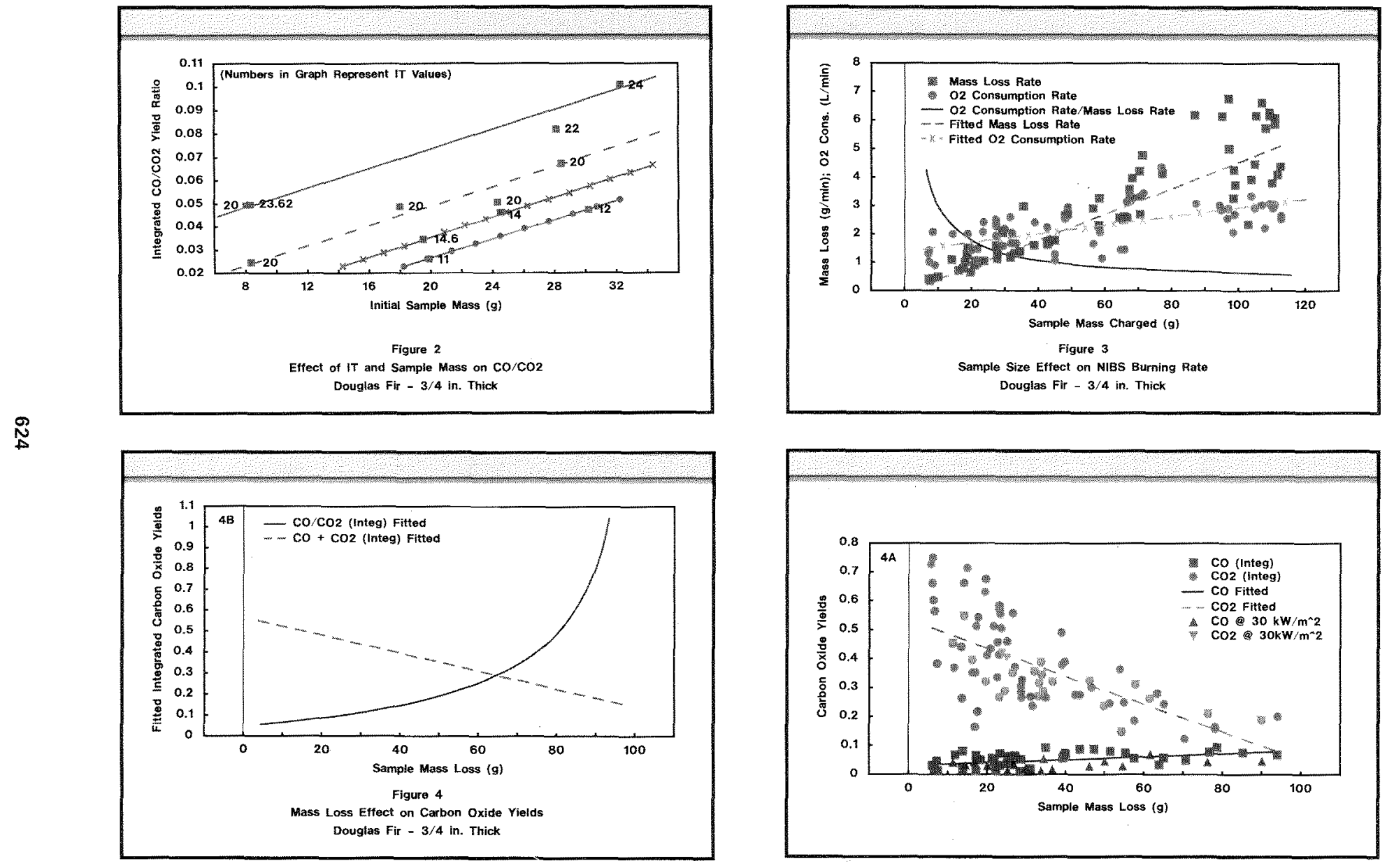